\title{
Application of solid waste for corrosion inhibition of steel in different media - A review
}

\author{
R.S. Abdel Hameed, ${ }^{1,2}{ }^{\circledR} *$ M.T. Qureshi ${ }^{1}$ and M. Abdallah ${ }^{3,4}$ \\ ${ }^{1}$ Basic Science Department, Preparatory Year, University of Ha'il, 1560, Hail, Kingdom \\ of Saudi Arabia \\ ${ }^{2}$ Chemistry Department, Faculty of Science, Al-Azhar University, 11884, Cairo, Egypt \\ ${ }^{3}$ Chemistry Department, Faculty of Science, Umm Al-Qura University, Makkah \\ Mukaramha, Kingdom of Saudi Arabia \\ ${ }^{4}$ Chemistry Department, Faculty of Science, Benha University, Benha, Egypt \\ *E-mail: mredars2@yahoo.com
}

\begin{abstract}
The present review is intended to report a series of works aimed to alleviate of the environmental pollution by converting plastic waste into useful products, and to evaluate the inhibition action of plastic waste on the corrosion of steel alloys, in different aqueous media. poly(ethylene terephthalate), PET plastic waste was used as cheap and safe corrosion inhibitors for steel in hydrochloric acid, sulfuric acid, acetic acid, formic acid, nitric acid corrosive media, and in aqueous saline corrosive medium. The present part reports the evaluation of PET waste and their modified products as corrosion inhibitors for steel in different media by chemical and electrochemical measurements. The review summarizes all scientific efforts and highlight the new method introduced by R. Abdel Hameed which is a novel idea involved the green recycling of plastic waste via a solvent free green method and using the modified product obtained as green corrosion inhibitors.
\end{abstract}

Keywords: waste recycling, steel corrosion, weight loss, electrochemistry, green synthesis, PET, green inhibitors.

Received: October 3, 2020. Published: January 29, 2021

doi: $\underline{10.17675 / 2305-6894-2021-10-1-4}$

\section{Introduction}

The recycling of plastic waste and use of their modified products as corrosion inhibitors for steel are limited. The use of plastic waste and their modified derivatives as corrosion inhibitors can be traced back to 2006's when R.S. Abdel Hameed and coworkers prepare some water soluble surfactant derived from plastic waste, this surfactant were evaluated as corrosion inhibitors for $\mathrm{C}$-steel in 1.0 M hydrochloric acid corrosive media, [1-11]. The application of plastic waste as corrosion inhibitors include the synthesis of new compounds with new structural properties from PET in an effort to improve their efficiencies in field of protection of steel from corrosion [1-10] through a series of work aimed to convert the PET plastic waste into corrosion inhibitors for metals and alloys in different media [1-11]. In the 1980's, polyethylene terephthalate (PET) began to be used popularly for the production of 
disposable soft drink bottles and in 1987, more than 700 million pounds of PET were consumed in their production [11]. As a result of the diversity of its applications in a high volume of consumer products, large amount of PET waste is also generated, which includes polymer manufacturing waste as well as the products after the end of their useful life. PET is a worldwide used polymer, and packaging is one of its most important applications. Due to its high resistance to the atmospheric and biological agents, this polymer is not considered as biodegradable. PET is not a hazardous product, but its waste quantity increases drastically. With the increasing pressure of keeping, the environmental clean. Recycling of PET waste is an eco-friendly manner is the only solution. PET waste can be recycled by different methods like physical recycling and chemical recycling. Chemical recycling is the reaction of PET with various reagents to obtain products that are used in the chemical industry [12], the chemical recycling of PET has been the subject of keen interest as a valuable feedstock for different chemical processes. During chemical recycling, PET waste can be depolymerised to base monomers or oligomers. With the use of solvent of depolymerization, generally called solvolysis of polymer, methanolysis [13-15] and glycolysis [16, 17] are the main possible routes. Hydrolysis [18-22] of PET is also possible using water under pressure. Aminolysis is another method of chemical degradation of PET, which has been little explored as compared to other techniques.

Steel is widely used as the constructional material in most of the major industries particularly in food, petroleum, power production, chemical and electrochemical industries, especially due to its excellent mechanical properties and low cost. The major problem of steel is its dissolution in acidic medium.

Corrosion of steel in acidic aqueous solutions is one of the major areas of concern in many industries where in acids are widely used for applications such as acid pickling, acid cleaning, acid descaling, and oil well acidizing. Because of general aggressiveness of acid solution, the materials of construction are being corroded easily [42-53].

Corrosion is an afflicting problem associated with every use of metals. The damage by corrosion results in highly cost for maintenance and protection of materials used. Metals generally tend to move to its original state by corrosion process because Corrosion is a thermodynamically feasible process as it is associated with decrease in Gibb's free energy. Development of methods to control corrosion is a challenge to scientists working in this area [42-52]. Amongst various methods developed for corrosion protection, use of inhibitor is an attractive and most practical method for the protection of metals in contact with corrosion medium. Inhibitors reduce the corrosion of metallic materials by controlling the metal dissolution and consumption [42-46].

Acid solutions are used for pickling, chemical, and electrochemical etching of metals, acidization of oil wells and in cleaning of scales because it is more economical, efficient and trouble-free, compared to other mineral acids [23, 24]. It is very important to add corrosion inhibitors to prevent metal dissolution and minimize acid consumption [25-27]. Most wellknown acid inhibitors are organic compounds containing nitrogen, sulfur and oxygen atoms. The inhibiting action exercised by organic compounds on the dissolution of metallic species 
is normally related to interactions by adsorption between the inhibitors and the metal surface. This process is considered as interface inhibition, according to Fischer's classification $[28,29]$. The surfactant inhibitor obtained from waste has many advantages such as high inhibition efficiency, low price, low toxicity, Available, renewable and easy production [3035]. The adsorption of the surfactant on the metal surface can markedly change the corrosion resisting property of the metal $[36,37]$, and so the study of the relationship between the adsorption and corrosion inhibition is of great importance. The present review article report and highlight the intensive efforts underway to develop new corrosion inhibitors starting from PET waste and their modified products and oligomer surfactants was used as a cheap and save corrosion inhibitors for steel in aqueous medium.

\section{Modified plastic waste as corrosion inhibitors for steel}

In this part, it is intended to report a series of works aimed to alleviate of the environmental pollution by converting plastic waste into useful products, and to evaluate the inhibition action of plastic waste on the corrosion of some steel alloys, in different aqueous media. [111], in 2006's, R.S. Abdel Hameed and coworkers introduce a new idea for using PET plastic waste as a cheap and safe corrosion inhibitor for steel in hydrochloric acid, sulfuric acid, acetic acid and nitric acid corrosive media, and also in aqueous $\mathrm{NaCl}$ corrosive medium. [111]. The application of plastic waste as corrosion inhibitors include the synthesis of new compounds with new structural properties from PET in an effort to improve their efficiencies in field of protection of steel from corrosion. In this respect: H. Shehata, H. Abdelbary, S. Abdelsalam, A. Salem, A.M. Atta, and R.S. Abdel Hameed try to modify PET waste as follows:

1. The PET waste converted into glycolysed products via glycolysis reaction by using TEA and DEA. With molar ratio 1:1 (wt. \% of PET to wt. \% of the used amines). These glycols used to convert PET into water soluble oligomers and act as the solvent of PET.

2. These glycolysis products are utilizing in synthesis of polymeric surfactants having different hydrophile-lipophile balances HLB.

3. Surfactants are produced from reaction of produced oligomers with polyethylene glycol, PEG, and stearic acid (SA).

4. These surfactants used as corrosion inhibitors for carbon steel alloy in presence of $1 \mathrm{M}$ $\mathrm{HCl}$ in aqueous solution. Using weight loss, and electrochemical measurements.

5. Evaluation of the prepared surfactants from waste as corrosion inhibitors at different temperatures.

In 2012, H. Shehata, H. Abdelbary, S. Abdelsalam, A. Salem, A.M. Atta, and R.S. Abdel Hameed [10] were able to conclude that

1. Nonionic surfactants are produced from reaction of the produced oligomers from PET waste with PEG, having M. wt. 400, 1000 and 4000, in presence of $\beta$, $\beta^{\prime}$-dichloro diethyl ether as a linking agent and $\mathrm{NaOH}$ as a catalyst. 
2. Inhibition efficiencies increase by an increase in inhibitor concentration and an increase in temperature up to $50^{\circ} \mathrm{C}$.

3. The uniform increasing inhibition efficiency as the function of concentration are dealing with adsorption phenomenon and the adsorption of all additives obeys the Langmuir adsorption isotherm. The negative values of enthalpies identifies that the adsorption is a physic-chemical adsorption type.

4. All entropy parameters for adsorption of inhibitors molecules on steel are positive and increase by increasing the temperature which indicate that the inhibitors more oriented and more ordered on the surface of the metal.

5. Activation energy increases with addition of inhibitors. It is shown that physical adsorption occurs in the first stage.

6. GT-EO90-SA shows an inhibiting effect on the corrosion of carbon steel in $1.0 \mathrm{M} \mathrm{HCl}$ which increases with inhibitor concentration.

7. The activation parameters of the dissolution $(E, \Delta H$ and $\Delta S$ ) were calculated and showed that the used inhibitors decrease the rate of corrosion.

In 2008, R.S. Abdel Hameed, Sh. Metwally, S. Abdelsalam and H. Al Shafy [29] were able to prepare and modify PET with Diethanolamine and Triethanolamine having 1:2 wt. \% of PET: wt. \% of DEA or wt. \% TEA, in presence of manganese acetate as a catalyst. The prepared inhibitors from waste were purified and characterization by FT-IR and ${ }^{1} \mathrm{H}$ NMR. The inhibition action of the prepared compounds $\left(D_{2} \& T_{2}\right)$ on the corrosion of carbonsteel which used in the manufacture of petroleum pipelines in nitric acid was evaluated, at different concentrations of inhibitors from $(50-250 \mathrm{ppm})$ and different temperatures, ranged from $(303-333 \mathrm{~K})$. The polarization curves indicate that these compounds may act as mixedtype inhibitors. The adsorption isotherm of the prepared compounds on C-steel was found to follow the Langmuir adsorption isotherm and they obey El-Awady isotherm. The values of activation energies, $\left(E_{\mathrm{a}}^{*}\right)$, and all thermodynamic activation parameters which determined and indicating that the type of adsorption of $\mathrm{D}_{2}, \mathrm{~T}_{2}$ derived from PET waste on the steel surface was chemical adsorption.

In 2009, R.S. Abdel Hameed et al. [30] report the use of ethoxylated poly(ethylene terephthalate) derived from plastic waste as corrosion inhibitors for C-Steel in $1.0 \mathrm{M}$ acetic acid solutions, the inhibition efficiency of ethoxylated derivatives (derived from waste) was determined using weight loss measurements as well as potentiodynamic polarization technique. It was concluded that:

1. All studied ethoxylated oligomers are excellent inhibitors and act as a mixed type inhibitor for carbon steel corrosion in acetic acid solution.

2. Inhibition efficiencies increased by increasing inhibitor concentration (from $84 \%$ to $92 \%$ ) and by increasing temperatures up to $333 \mathrm{~K}$.

3. All entropy parameters for adsorption of inhibitors molecules on steel are positive and increase by increasing the temperature which indicates that the inhibitors being more oriented and more ordered on the surface of the metal. 
4. The activation parameters of the adsorption $\left(E^{*}, \Delta H^{*}\right.$ and $\left.\Delta S^{*}\right)$ were calculated and showed that the used inhibitors decrease the rate of corrosion.

5. The adsorption of these inhibitors on steel surface obeys Langmuir's adsorption isotherm.

6. The increase in the ethylene oxide unites in the molecular structure leads to more inhibition efficiency. And the corrosion inhibition efficiency reach to $92 \%$.

In 2010, Atta, Migahed et al. synthesized a new water soluble corrosion inhibitor from recycled poly(ethylene terphethalate). Polyethylene terephthalate (PET) waste was depolymerized by triethanolamine into glycolyzed product (GT), followed by esterification with bromoacetic acid in the presence of manganese acetate as a catalyst to give (GT-Br). The obtained ester was reacted with thiourea to give thiol derivative (GT-SH). The effectiveness of the synthesized compound as corrosion inhibitor for API XL65 carbon steel, in $2.0 \mathrm{M}$ hydrochloric acid solution was investigated by various electrochemical techniques such as open circuit potential, potentiodynamic polarization and electrochemical impedance spectroscopy (EIS). The results of these investigations showed enhancement in inhibition efficiencies with the increasing of inhibitor concentration. The protective film formed on carbon steel surface was analyzed using an energy dispersive X-ray analysis (EDX) technique. Also, scanning electron microscope (SEM) was used to study the surface morphology of steel surface in the absence and presence of $400 \mathrm{ppm}$ of the additive [41].

In 2011 's, R.S. Abdel Hameed introduce new water soluble amide derived from PET waste, [36] in this respect: soft drink bottles was subjected to depolymerization through aminolysis using mono ethanol amine, (MEA) in the presence of sodium acetate as a catalyst the product of poly(bis(2-hydroxyethylene) terephthalamide. (PHETA) was evaluated as corrosion inhibitors for $\mathrm{C}$-Steel in $1.0 \mathrm{M} \mathrm{HCl}$ by using weight loss, open circuit potential and potentiodynamic polarization measurements. The polarization curves indicate that these compound (amide) act as mixed type inhibitors. The inhibition efficiency increase with increasing the concentration of the inhibitors and decreases with increasing the temperature, the values of activation energy $\left(E_{\mathrm{a}}\right)$ and free energy of adsorption $\left(\Delta G_{\mathrm{ads}}\right)$ indicated that the type of adsorption was chemical adsorption. The inhibition occurs through adsorption of the inhibitor molecules on the metal surface without modifying the mechanism of corrosion process. The adsorption of the inhibitor on C-Steel surface was found to follow the Langmuir adsorption isotherm. Scanning electron microscope (SEM) was used to study the surface morphology of steel surface in absence and presence of $200 \mathrm{ppm}$ of the used inhibitor derived from waste.

In 2012, Abdel Hameed et al. was studied the corrosion of mild steel in $\mathrm{NaCl}$ solutions and effect of recycled plastic waste inhibitors [37]. In this respect: recycled polyethylene terphthalate (PET) with both of diethanolamine (DEA) and Triethanolamine (TEA) (ratios of $1: 2$ wt. \%) followed by esterification with stearic acid, to give $\left(\mathrm{D}_{2} \mathrm{~S}\right.$ and $\left.\mathrm{T}_{2} \mathrm{~S}\right)$. the corrosion inhibition effect of $\left(\mathrm{D}_{2} \mathrm{~S}\right.$ and $\left.\mathrm{T}_{2} \mathrm{~S}\right)$ was determined using weight loss, potentiodynamic polarization techniques and open circuit potential measurements. The 
results showed that the inhibition of the prepared recycled compounds $\left(D_{2} S \& T_{2} S\right)$ occurs through adsorption of the inhibitor molecules on the metal surface and the inhibition efficiency was found to increase with increasing the inhibitor concentrations and temperature as well as these inhibitors act as mixed-type. The adsorption of these compounds on the metal surface is found to obey Langmuir adsorption isotherm. Thermodynamic functions for both dissolution and adsorption processes were calculated. The obtained results from weight loss and potentiodynamic polarization techniques are in a good agreement.

In 2013's, R.S. Abdel Hameed et al. were studied the corrosion inhibition of carbon steel in $1.0 \mathrm{M}$ formic acid by poly(oxyethylene)terphthylamine derived from plastic waste. In this respect: polyethylene terphthalate waste depolymerized with diethanolamine to give the corresponding amine, etherfication of the produced hydroxylamine with different molecular weight of poly ethylene glycol (PEG1000, PEG4000) gives the corresponding poly(oxyethylene)terephthalamines which were separated, identified and evaluated as corrosion inhibitors for carbon steel in $1.0 \mathrm{M}$ methanoic acid, the corrosion inhibition efficiency was determined at different concentrations of the used inhibitors by chemical techniques (weight loss) and electrochemical techniques (potentiodynamic polarization and open circuits potential). The corrosion inhibition efficiency depends on the inhibitor concentration and type, the protection efficiency increase with increasing the concentration and the number of ethylene oxide units in order of $\left(\mathrm{Dn}_{22}\right.$ and $\left.\mathrm{Dn}_{90}\right)$, The inhibition was assumed to occur via the adsorption of the inhibitors on the metal surface. And obey Langmuir adsorption isotherm. The polarization curves indicate that these compounds at as mixed-type inhibitors. Addition of inhibitors molecules to the corrosive medium produces a negative shift in the open circuit potential. Effects of temperatures on the inhibition efficiency were studied, thermodynamic parameters were computed and discussed, it was found that the obtained data from different techniques are in good agreement, and the increase in the numbers of ethylene oxide units in the molecular structure of the modified plastic waste leads to increase inhibition efficiency.

In 2016, the all scientific efforts in the field of using plastic waste as green corrosion inhibitors towards metals have been reviewed by R.S. Abdel Hameed, when he collects and summarizes his studies and other scientist studies in the good review article published in a material science Indian journal [9].

In 2017, R.S. Abdel Hameed introduce (R. Abdel Hameed green method [54]) which is a novel idea involved the green recycling of plastic waste via a solvent free green method and using the modified product obtained from the green synthesis process as corrosion inhibitors for carbon steel in acidic medium using chemical, electrochemical, adsorption, and thermodynamic studies [54]. From his experimental study he concluded the following:

1. PET waste could be depolymerized using propylene glycol in the presence of manganese dioxide catalyst to give Bis(hydroxy propylene) terephthalate, BHPT, the process is solvent free efficient green process.

2. BHPT compound act as mixed inhibitor for carbon steel in $1.0 \mathrm{M} \mathrm{H}_{2} \mathrm{SO}_{4}$. 
3. The corrosion inhibition efficiency increase with inhibitor concentration and decrease with temperatures.

4. The impedance of the inhibited solution has increased with the increase in the concentration of the inhibitor.

5. SEM observations of the steel surface showed that a protective film of inhibitor molecules is formed on the carbon steel surface.

6. The protective film formed confirms the observed high percentage inhibition efficiency $(\% I E)$ of inhibitor (BHPT) derived from plastic waste.

7. The volume of the evolved hydrogen decrease gradually with increasing inhibitor concentration which may due to inhibitor compounds control the hydrogen evolution reaction.

8. The data obtained from different techniques are in good agreement proving that the obtained compounds from plastic waste via a solvent free green synthesis method (R. Abdel Hameed green method) are highly efficient green corrosion inhibitors for steel in acidic medium [54].

In 2020 R.J. Tuama et al. studied the corrosion inhibition of C-steel material in acidic media using modified poly (ethylene terephthalate) waste [55]. The depolymerization of polyethylene terephthalate (PET) waste was achieved by propane-1,3-dithiol into bis(3mercaptopropyl) thioterephthalate (BTPTT) product. The product was characterized by FTIR and GPC. The thermal properties (TGA, DTA) indicated that the prepared compound was thermally stable up to $150^{\circ} \mathrm{C}$, the prepared stable product was evaluated as corrosion inhibitor for steel in $0.1 \mathrm{~N} \mathrm{HCl}$ using Tafel plot in electrochemical technique at different concentrations and temperatures. The results of this work showed that the inhibition occurs through adsorption of the inhibitor molecules on the C-steel surface, and the adsorption of (BTPTT) on C-steel surface obeys the Langmuir adsorption isotherm and involves a chemisorption mechanism [55]. In 2020 R. Abdel Hameed, and coworkers were studied the green synthesis and characterization of nonionic surfactants derived from poly (ethylene terephthalate), PET, and calculate their thermodynamic parameters for micelization and adsorption at different temperatures in order to applied the higher adsorption prepared surfactants as corrosion inhibitors for metals and alloys in the future research projects [56].

Finally, the area of the research on the using of plastic waste as corrosion inhibitors for metals is of technical, economic, environmental, and ethical impact as soon as a vibrant area of the research work and considered as a recent subject as it started 2006 to 2020 so it is highly promising for many scientists and researchers.

\section{Conclusions}

Recycling of plastic waste as corrosion inhibitors for steel in different media are limited and traced back to 2006's by R.S. Abdel Hameed and coworkers. 
All the reported materials showed good inhibition efficiency for corrosion of steel in different aqueous media. Modified plastic waste show real promise as green corrosion inhibitors for steel alloys in aqueous corrosive media.

All water soluble polymeric surfactants obtained from PET are of great advantages for corrosion inhibition of steel in different media, which are biodegradable; do not contain heavy metals or other toxic compounds, inexpensive, readily available and renewable. As in addition to being environmentally friendly and ecologically acceptable, also give higher inhibition efficiency.

All obtained results from electrochemical and weight loss measurements are in good agreement with each other and indicate the possibility of using modified plastic waste as green corrosion inhibitors for steel in different corrosive media. the obtained compounds from plastic waste via a solvent free green synthesis method (R. Abdel Hameed green method) are highly efficient green corrosion inhibitors for steel in acidic medium and highly promise.

Finally, the area of the research on the use of plastic waste as corrosion inhibitors for metals is highly promising as shown by many researchers.

\section{Acknowledgments}

This research has been funded by Scientific Research Deanship at University of Ha'il, Saudi Arabia through project number (RG-191330).

\section{References}

1. R.S. Abdel Hameed, Evaluation of some water-based surfactants derived from plastic waste as corrosion inhibitors, for carbon steel alloy, Ph.D. Thesis, Al Azhar Univ., 2006.

2. R.S. Abdel Hameed, H.I. AL Shafey, S.A. Soliman and M.S. Metwally, Corrosion of Csteel alloy in $(0.1 \mathrm{M})$ Nitric acid in the presence of plastic waste as corrosion inhibitors, Al-Azhar Bull. Sci., 2008, 19, no. 2, 283-298. doi: 10.21608/absb.2008.10102

3. R.S. Abdel Hameed, A.S. Al Shafey and E.A. Ismail, Studies on corrosion inhibition of C-steel in 1M Acetic acid solutions by ethoxylated poly(ethylene terphthalate) derived from plastic waste, Al-Azhar Bull. Sci., 2009, 20, no. 1, 185-197. doi: 10.21608/ABSB.2009.7553

4. M. Atta Ayman, H.A. Shehata, H.M. Abd El Bary, S.A. Salam and R.S. Abdel Hameed, Recycled poly(ethylene terephthalate) waste oligomers as corrosion inhibitors of steel, Prog. Rubber, Plast. Recycl. Technol., 2007, 23, no. 4, 209-226. doi: 10.1177/147776060702300403

5. R.S. Abdel Hammeed, Recycling of plastic waste as corrosion inhibitors for steel in 0.5 M sulfuric acid, Al-Azhar International Scientific Conference, 2008.

6. R.S. Abdel Hameed, H.I. Al-Shafy and M. Atta Ayman, Modified poly(ethylenterphthalate) as corrosion inhibitors for $\mathrm{C}$-steel in $1 \mathrm{M} \mathrm{HCl}$, The $12^{\text {th }}$ International Conference on petroleum, mineral wealth and development, 2009. 
7. R.S. Abdel Hameed, H.A. Shehata, H.M. Abdelbary, S.A. Soliman, A.M. Salem and A.M. Atta, Evaluation of nonionic surfactants from plastic waste as corrosion inhibitors of carbon steel in $1 \mathrm{M} \mathrm{HCl,Mater.} \mathrm{Sci.,} \mathrm{2012,} \mathrm{8,} \mathrm{no.} \mathrm{7,} \mathrm{289-302.}$

8. R.S. Abdel Hameed and H.I. Al-shafey, Recycling of some plastic waste as green corrosion inhibitors for steel in $1 \mathrm{M}$ Phosphoric acid corrosive medium, Eurasia 12 conference, 2012.

9. R.S. Abdel Hameed, Recycling of plastic waste as green corrosion inhibitors for steel in different corrosive media, Mater. Sci.: Indian J., 2016, 14, no. 12, 503-509.

10. R.S. Abdel Hameed, H.I. AL-Shafey and O.A. Farghaly, Corrosion of mild Steel in $\mathrm{NaCl}$ solutions and effect of recycled plastic waste inhibitors, Res. Rev. Electrochem., 2012, 3, no. 2, 41-49.

11. R.S. Abdel Hameed, Aminolysis of polyethylene terephthalate waste as corrosion inhibitor for carbon steel in $\mathrm{HCl}$ corrosive medium, Adv. Appl. Sci. Res., 2011, 2, no. 3, 483-499.

12. T. Hirose, Y. Takai, N. Azuma et al., Polystyrene foams with dispersed catalyst for a design of recyclable plastics, J. Mater. Res., 1998, 13, 77-80. doi: 10.1557/JMR.1998.0011

13.G. Colomines, J. Robin and G. Tersac, Study of the glycolysis of PET by oligoesters, Polymer, 2005, 46, no. 10, 3230-3245. doi: 10.1016/j.polymer.2005.02.047

14. M. Alauddin, I.A. Choudhury, M.A. El Baradie and M.S.J. Hashmi, Plastics and their machining: A review, J. Mater. Process. Technol., 1995, 54, 40-46. doi: 10.1016/0924$\underline{0136(95) 01917-0}$

15. R.J. Müller, I. Kleeberg and W.D. Deckwer, Biodegradation of polyesters containing aromatic constituents, J. Biotechnol., 2001, 86, 87-95. doi: 10.1016/S01681656(00)00407-7

16. K. Ishihara and K. Ishida, Jpn. Pat. 11302227, 1999.

17. A. Vaidya and V. Nadkarni, Polyester polyols for polyurethanes from pet waste: Kinetics of polycondensation, J. Appl. Polym. Sci., 1989, 38, 1179-1192. doi: 10.1002/app.1988.070350317

18. S.R. Shukla and K.S. Kulkarni, Depolymerization of poly(ethylene terephthalate) waste, J. Appl. Polym. Sci., 2002, 85, 1765-1778. doi: 10.1002/app.10714

19. Y. Shiraishi, T. Hirai and I. Komasawa, A deep desulfurization process for light oil by photochemical reaction in an organic two-phase Liquid-Liquid extraction system, Ind. Eng. Chem. Res., 1998, 37, no. 1, 203-211. doi: 10.1021/ie970388f

20. A. Oku, Jpn. Pat. 1087529, 1998.

21. Sh.M. Elsaeed and R.K. Farag, Synthesis and characterization of unsaturated polyesters based on the aminolysis of poly(ethylene terephthalate), J. Appl. Polym. Sci., 2009, 12, no. 6, 3327-3336. doi: 10.1002/app.29527

22. J. Demarteau, I. Olazabal, C. Jehanno and H. Sardon, Aminolytic upcycling of poly(ethylene terephthalate) wastes using a thermally-stable organocatalyst, Polym. Chem., 2020, 11, 4875-4882. doi: 10.1039/D0PY00067A 
23. Pusztaszeri SF, US Pat. 4355175, 1982.

24. M. Abdallah, A. Fawzy, H. Hawsawi, R.S. Abdel Hameed and S.S. Al-Juaid, Estimation of water-soluble polymers (poloxamer and pectin) as corrosion inhibitors for carbon steel in acidic medium, Int. J. Electrochem. Sci., 2020, 15, 1-16. doi: $10.20964 / 2020.08 .73$

25.M. Abdallah, F.H. Al-abdali, E.M. Kamar, R. El-Sayed and R.S. Abdel Hameed, Corrosion inhibition of aluminum in $1.0 \mathrm{M} \mathrm{HCl}$ solution by some nonionic surfactant compounds containing five membered heterocyclic moiety, Chem. Data Collect., 2020, 28, 100407. doi: $10.1016 /$ j.cdc.2020.100407

26. R.S. Abdel Hameed, M. Alfakeera and M. Abdallah, Propoxylated fatty esters as safe inhibitors for corrosion of zinc in hydrochloric acid, Prot. Met. Phys. Chem. Surf., 2020, 56, no. 1, 225-232. doi: $10.1134 /$ S2070205120010025

27. P. Mahalakshmi, S. Rajendran, G. Nandhini, T. Umasankareswari and N. Renuga Devi, Inhibition of corrosion of mild steel in sea water by an aqueous extract of turmeric powder, Int. J. Corros. Scale Inhib., 2020, 9, no. 2, 706-725. doi: $10.17675 / 2305-6894-2020-9-2-20$

28. a. Dehghani, G. Bahlakeh, B. Ramezanzadeh and M. Ramezanzadeh, Experimental complemented with microscopic (electronic/atomic)-level modeling explorations of Laurus nobilis extract as green inhibitor for carbon steel in acidic solution, J. Ind. Eng. Chem., 2020, 84, 52-71. doi: 10.1016/j.jiec.2019.12.019

29. A.O. Yüce, Corrosion inhibition behavior of Robinia pseudoacacia leaves extract as a eco-friendly inhibitor on mild steel in acidic media, Met. Mater. Int., 2020, 26, no. 4, 456-466. doi: 10.1007/s12540-019-00509-7

30. N.R. Devi, N. Karthiga, R. Keerthana, T. Umasankareswari, A. Krishnaveni, G. Singh and S. Rajendran, Extracts of leaves as corrosion inhibitors - An overview and corrosion inhibition by an aqueous extract of henna leaves (Lawsonia inermis), Int. J. Corros. Scale Inhib., 2020, 9, no. 4, 1169-1193. doi: 10.17675/2305-6894-2020-9-4-2

31. A.S. Fouda, M.A. El-Morsy, A.A. El-Barbary and L.E. Lamloum, Int. J. Corros. Scale Inhib., 2016, 5, no. 2, 112-131. doi: 10.17675/2305-6894-2016-5-2-2

32. V.I. Vigdorovich, L.E. Tsygankova, E.D. Tanygina, A.Yu. Tanygin and N.V. Shel, Int. J. Corros. Scale Inhib., 2016, 5, no. 1, 59-65. doi: 10.17675/2305-6894-2016-5-1-5

33. P.N. Devi, J. Sathiyabama and S. Rajendran, Int. J. Corros. Scale Inhib., 2017, 6, no. 1, 18-31. doi: 10.17675/2305-6894-2017-6-1-2

34. V.P. Grigor'ev, E.V. Plekhanova, E.G. Drogan, L.D. Popov and T.G. Plekhanova, Inhibiting action of amino-heterocyclic compounds under conditions of iron corrosion in sulfuric acid solutions, Int. J. Corros. Scale Inhib., 2020, 9, no. 2, 584-594. doi: $\underline{10.17675 / 2305-6894-2020-9-2-13}$

35. M. Tabatabaei majd, R. Naderi and B. Ramezanzadeh, Promotion of the active barrier protection function of epoxy ester coating steel system utilizing differently synthesized hybrid pigment through zinc acetylacetonate tailored with green inhibitor molecules, Prog. Org. Coat., 2020, 138, 105380. doi: 10.1016/j.porgcoat.2019.105380 
36. S. Chen, B. Zhu and X. Liang, Corrosion inhibition performance of coconut leaf extract as a green corrosion inhibitor for X65 steel in hydrochloric acid solution, Int. J. Electrochem. Sci., 2020, 15, no. 1, 1-15. doi: 10.20964/2020.01.39

37. M. Barbouchi, B. Benzidia, M.E. Idrissi and M. Choukrad, Iron corrosion green inhibition in a $3 \% \mathrm{NaCl}$ solution, by leaves extract from pistacia terebinthus L. growing wild in Morocco, Port. Electrochim. Acta, 2020, 38, no. 3, 175-184. doi: 10.4152/pea.202003175

38. S.M. Al-Salem, P. Lettieri and J. Baeyens, Recycling and recovery routes of plastic solid waste (PSW): A review, Waste Manage., 2009, 29, no. 10, 2625-2643. doi: 10.1016/j.wasman.2009.06.004

39. T. Chilton, S. Burnley and S. Nesaratnam, A life cycle assessment of the closed-loop recycling and thermal recovery of post-consumer PET, Resour., Conserv. Recycl., 2010, 54, no. 12, 1241-1249. doi: 10.1016/j.resconrec.2010.04.002

40. A.H. Yasir, A.S. Khalaf and M.N. Khalaf, Preparation and characterization of oligomer from recycled PET and evaluated as a corrosion inhibitor for C-Steel material in $0.1 \mathrm{M}$ HCl, Open J. Org. Polym. Mater., 2017, 7, no. 1, 1-15. doi: 10.4236/ojopm.2017.71001

41. B.D.B. Tiu and R.C. Advincula, Polymeric corrosion inhibitors for the oil and gas industry: Design principles and mechanism, React. Funct. Polym., 2015, 95, 25-45. doi: 10.1016/j.reactfunctpolym.2015.08.006

42. A.A. Naser, A.S. Al-Mubarak and H.Z. Al-Sawaad, Synthesis, characterization and evaluation of some graphene oxide derivatives and their application as corrosion inhibitors for carbon steel alloy type $\mathrm{C} 1025$ in hydrochloric acid, Int. J. Corros. Scale Inhib., 2019, 8, no. 4, 974-997. doi: 10.17675/2305-6894-2019-8-4-11

43. R.S. Abdel Hameed, E.A. Ismail, H.I. Al-Shafey and A.Abbas. Mohamed, Expired indomethacin therapeutics as corrosion inhibitors for carbon steel in $1.0 \mathrm{M}$ hydrochloric acid media, J. Bio- Tribo-Corros., 2020, 6, 114. doi: 10.1007/s40735-020-00403-5

44. R.S. Abdel Hameed, N.S. Elmetery, N.F. Alshemary and H.A. Shehata, Recycling of some plastic waste as green corrosion inhibitors for steeling $1 \mathrm{M}$ phosphoric acid, Mater. Sci. J., 2016, 14, no. 11, 417-425.

45. R.S. Abdel Hameed, Schiff's bases as corrosion inhibitor for aluminum alloy in hydrochloric acid medium, Tenside, Surfactants, Deterg., 2019, 56, no. 3, 209-215. doi: $\underline{10.3139 / 113.110622}$

46. M.M. Ibrahim, R.S. Abdel Hameed, Abd-Al.H. Abu-Nawwas, S.E. Mohamad, Schiff's bases and their metal complexes as corrosion inhibitors for aluminum alloys in corrosive media, J. Org. Chem., 2014, 10, no. 7, 271-281. doi: 10.1002/chin.201621235

47. R.S. Abdel Hameed. Expired drugs as corrosion inhibitors for metals and alloys, Phys. Chem.: Indian J., 2013, 8, no. 4, 146-149.

48. R.S. Abdel Hameed, Ranitidine drugs as non-toxic corrosion inhibitor for mild steel in hydrochloric acid medium, Port. Electrochim. Acta, 2011, 29, no. 4, 273-285. doi: $\underline{10.4152 / \text { pea.201104273 }}$ 
49. R.S. Abdel Hameed, E.H. Aljuhani, R. Felaly and A.M. Munshi, Effect of expired paracetamol- $\mathrm{Zn}^{+2}$ system and its synergistic effect towards iron dissolution inhibition and green inhibition performance, J. Adhes. Sci. Technol., 2020, 34, no. 19, 1-36. doi: 10.1080/01694243.2020.1826801

50. R.S. Abdel Hameed, E.H. Aljuhani, A.H. Al-Bagawi, A.H. Shamroukh and M. Abdallah, Study of sulfanyl pyridazine derivatives as efficient corrosion inhibitors for carbon steel in $1.0 \mathrm{M} \mathrm{HCl}$ using analytical techniques, Int. J. Corros. Scale Inhib., 2020, 9, no. 2, 623-643. doi: 10.17675/2305-6894-2020-9-2-16

51. R.S. Abdel Hameed and A.H. Shamroukh, Synthesis, characterization, and evaluation of some acyclic S-nucleosides of pyrazolo[3,4-d]pyrimidine-thiones as corrosion inhibitors for carbon steel in hydrochloric acid, Int. J. Corros. Scale Inhib., 2017, 6, no. 3, 333-348. doi: $\underline{\text { 10.17675/2305-6894-2017-6-3-8 }}$

52. R.S. Abdel Hameed, A.H. Al-Bagawi, H.A. Shehata, A.H. Shamroukh and M. Abdallah, Corrosion inhibition and adsorption properties of some heterocyclic derivatives on C-Steel surface in HCl, J. Bio- Tribo-Corros., 2020, 51, no. 6, 1-11. doi: 10.1007/s40735-020-00345-y

53. R.S. Abdel Hameed, Cationic surfactant $-\mathrm{Zn}^{+2}$ system as mixed corrosion inhibitors for carbon steel in sodium chloride corrosive medium, Port. Electrochim. Acta, 2018, 36, no. 4, 271-283. doi: 10.4152/pea.201804271

54. R.S. Abdel Hameed, Solvent free glycolysis of plastic waste as green corrosion inhibitor for carbon steel in sulfuric acid, J. New Mater. Electrochem. Syst., 2017, 20, 141-149. doi: $10.14447 /$ jnmes.v20i3.272

55. R.J. Tuama, M.E. Al-Dokheily and M.N. Khalaf, Recycling and evaluation of poly(ethylene terephthalate) waste as effective corrosion inhibitors for C-steel material in acidic media, Int. J. Corros. Scale Inhib., 2020. 9, no. 2, 427-445. doi: 10.17675/2305-6894-2020-9-2-3

56. R.S. Abdel Hameed, M.F.H. Abd El-Kader, M.T. Qureshi, M. Al Elaimi and O.A. Farghaly, Green synthesis for nonionic surfactants from poly(etheleneterphthalate) plastic waste, Egypt. J. Chem., 2020, 64, no. 2, 5-8. doi: 10.21608/EJCHEM.2020.45554.2928 